REVISTA ANDALUZA DE ANTROPOLOGÍA

NÚMERO 17: ESTRATEGIAS SUBALTERNAS EN AMÉRICA LATINA: RECONFIGURANDO LA IDENTIDAD PARA ARTICULARSE A UN MUNDO GLOBAL. SUBALTERN STRATEGIES IN LATIN AMERICA: RECONFIGURING IDENTITY TO BE ARTICULATED TO THE GLOBAL WORLD.

SEPTIEMBRE DE 2019

ISSN 2174-6796

[pp. 137-141]

http://dx.doi.org/10.12795/RAA.2019.17.07

\title{
VENTURA, MONTSERRAT; MATEO, JOSEP LLUÍS; CLUA, MONTSERRAT (2018). Humanidad. Categoría o condición. Un viaje antropológico. Barcelona: Bellaterra.
}

\author{
Yolanda Aixelà Cabré \\ IMF-CSIC Barcelona
}

El presente volumen recoge los retos teóricos, metodológicos y etnográficos del estudio de la Humanidad desde una perspectiva antropológica y multidisciplinar, en un siglo XXI en el que los Posthumanismos mantienen cierto protagonismo en la investigación científica. Este libro se inserta en una tradición renovadora y valiente que recupera eficazmente las virtudes del concepto e idea de Humanidad para revisarlos en profundidad, conectándolos con otras experiencias culturales en Europa, Asia, África y Latinoamérica. De una edición extraordinariamente cuidada, el libro permite conocer la excelente producción científica de un grupo de investigadores de dentro y fuera del estado español que se aproximan a la Humanidad desde una perspectiva Descoliana: V. Stolcke, E. Ramírez-Goicoechea. P. San Mateo y P. Domínguez, E. Porqueras, A. Van den Bogaert, M. Martínez Mauri, D. Branca, J. J. Rivera Andía, E. Carlos Ríos, A. Surrallés, A. Coello y D. Atienza de Frutos, V. Gaibar, M. Ojeda, M. Ventura, J.LL. Mateo y M. Clua.

El prólogo de V. Stolcke y la introducción de M. Ventura, J.LL. Mateo y M. Clua, suponen una verdadera oportunidad para comprender el impacto y dimensión del trabajo. Libro inserto en una tradición posthumanista y postcolonial, permite formular nuevas preguntas a viejas cuestiones, a la vez que abre campos nuevos en la biotecnología. Como señalan sus editores en la introducción, el libro se ha organizado sobre regiones simbólicas "donde ha dominado una forma de humanidad separada de lo humano (Parte I), una forma de humanidad continua (Parte II), y formas supuestas de continuidades discontinuas (Parte III), todas ellas con matices" (p.32).

La primera sección del libro se titula "Humanidades discontinuas". V. Stolcke, con su provocativo trabajo "A propósito del sexo. Viejas ideas y nuevas técnicas de cómo 
engendrar seres humanos", se pregunta cómo van a transformar las nuevas tecnologías la categorización sexual clásica, y si la clonación va contra natura. Tras poner de relieve que la naturaleza no es algo determinado, Stolcke contrapone razón genealógica a individualismo genético. De entre sus diversas conclusiones, destacar que "ese mismo deseo de formar una familia y de tener un/a hijo/a propio perfecto/a... se trata de una de las manifestaciones de una sociedad neo-liberal intensamente competitiva a la vez que muy desigual..." (p.63). Por su parte, E. Ramírez-Goicoechea, con su capítulo "El humano naturalizado de las ciencias de la vida. Epigenética, biología y prácticas material-simbólicas", aborda cómo los científicos de la vida (especialistas en los campos de la Genómica, Genéticas, entre otros) abordan las epistemo-ontologías. Especialmente interesada en estudiar la herencia epigenética, concluye que los expertos en su mayoría "se adscriben a un reduccionismo biológico-genético" (p.95). P. San Mateo y P. Domínguez, titulan su aportación "Concepciones parciales del ser humano en la ciencia" en el que ofrecen una aproximación etnográfica en un instituto de investigación estudiando "la cosmovisión, los fundamentos epistemo-ontológicos, teóricos y metodológicos del paradigma científico (p.103). En su opinión el conocimiento aparece como demasiado fragmentado por lo que consideran que debería haber un mayor intercambio y debate conceptual entre diversas disciplinas y enfoques que investigan el mundo de lo humano (p.119). La justa dedicatoria de este libro es a título póstumo para el entrañable investigador E. Porqueras i Gené. En su capítulo "Parentesco y biotecnologías", Porqueras abordó la difícil definición del parentesco, la trascendencia del embrión, entendiéndolo también como el elemento que reúne al mismo tiempo la individuación y la subjetividad. Como señalaba, "los debates escolásticos alrededor de la fabricación del embrión han proporcionado materiales que permiten ilustrar la articulación siempre presente entre, por una parte, el cuerpo del parentesco sometido a las reglas de la sexualidad... y por otra parte, instancias trascendentes indispensables para la fabricación de la persona" (p.135).

La segunda sección del libro se titula "Humanidades continuas". A. Van den Bogaert inicia la sección con el trabajo "Continuidad interior, discontinuidad corporal: la humanidad fragmentada en el Himalaya indio", en el que tras especificar los límites de la investigación respecto al hinduismo, los clanes y las castas, se adentra en cómo se crea al ser humano discerniendo entre cuerpo, espíritu, alma y nombre. En su opinión "la embriología, la formación del ser humano, significa el ensamblaje progresivo de estos elementos y su interconexión" (p. 160). M. Martínez Mauri presenta "Fiscalidad e interioridad en la construcción social de las personas humanas. Reflexiones en torno a la concepción de la sangre entre los gumas", y en su texto aborda el giro ontológico en el mundo indígena americano. Centrada en la sangre como substancia vital, analiza las nociones de interioridad y fiscalidad de la vida, abogando por el reconocimiento de personas humanas, por lo que sugiere "pensar la experiencia guna de la vida sin dicotomías, sin separar de forma tajante la fiscalidad de la interioridad. En la conformación de las 
personas humanas (dules), no parece operar esta separación” (p. 180). Por su parte, D. Branca con "Una aproximación a la noción de humanidad en el altiplano aymara de Puno, Perú, estudia los componentes anímicos de la persona y la humanidad como condición y considera que "es necesario insertar la noción de humanidad, a pensarse no como concepción de la realidad compartida por todos y todas, sino sujeta a cambios y reajustes debido a la experiencias de las mismas personas" (p.196). J. J. Rivera Andía escribe "Humanos y no humanos en la música indígena de los Andes contemporáneos", en el que analiza algunas dificultades metodológicas para la comprensión de la alteridad musical en los Andes, observando de qué manera participan las entidades no-humanas. En su opinión, es en la música que "las entidades no humanas entendidas como peligrosas o escogidas por su aspecto de confrontación, está en la base de... la noción de humanidad en los Andes" (p.209). E. Carlos Ríos titula su investigación "Chawpinchay-tinkunchay: el punto de encuentro discernible", texto que busca la unión entre ambos conceptos, analizándolos como nudos ya que "a partir de las divisiones y clasificaciones del mundo, cada cultura va desarrollando su propia construcción histórica y cultural” (p.227). M. Ventura cierra la sección con su "Nos habéis aportado la humanidad'. Una antropología de la vida y la muerte en una sociedad del occidente del Ecuador”, capítulo que estudia los seres tsachila, cómo se presenta la vida humana tras la muerte y cómo participa en la construcción de humanidad. En sus conclusiones, $\mathrm{V}$ entura señala que algunas prácticas rituales refuerzan fronteras porque se trata de "un sistema ritual tradicional y vivo, que no anula... el carácter relacional del ser humano, la humanidad compartida. Sin embargo... algunos indicios sugieren que el dualismo naturalista, llegado de la mano del cristianismo, está aportando una humanidad individuada" (p. 248).

Inicia la tercera sección del libro "(Des)encuentro de humanidades", A. Surrallés con el capítulo titulado "La traducción de las nociones de 'humanos' y 'persona' en la lexicografía de la América colonial", donde estudia la persona jesuística en los Andes y el Paraguay del siglo XVII y cómo debería traducirse la 'persona' novohispana. Al reflexionar sobre el hecho de que "encontramos una traducción para persona sin que esto suscite ninguna inquietud. Igualmente, el creciente número de textos antropológicos sobre la noción de persona amerindia... tampoco parece poner en duda su traductibilidad dado que recurren a términos amerindios", plantea que tal vez se haya producido un enorme malentendido cultural y sea necesario revisar la noción de persona (p. 264). A. Coello y D. Atienza de Frutos con su trabajo "Buenos y malos muertos' en las islas Marianas (siglos XVII y XVIII)", desarrollan ontologías micronesias en la construcción entre buenos y malos muertos. Para ellos, "el pensamiento de los seres humanos que comparten un lugar, un espacio y una forma de estar en el mundo se expresa...principalmente a través del lenguaje..." (p. 269). La constatación de que en los censos la mayoría de indígenas chamorros poseía nombres peyorativos, y que estos nombres marcan una continuidad en el pensamiento indígena, les lleva a concluir que "es fundamental tener presente que 
existió una continuidad en la experiencia indígena que no fue erradicada por el contacto con los europeos" (p. 281-2). Por su parte M. Clua con "Los límites de la humanidad compartida: colonialismo, esclavitud y racismo en Catalunya", señala la participación colonial catalana desde el tráfico de esclavos trasatlántico, poniendo de relieve la figura de los indianos. También se centra en el tema de los zoos humanos y el negro de Banyoles como formas coloniales de expresar alteridad. Su interés es destacar "prácticas deshumanizadoras relacionadas con la colonización y el racismo, como son la esclavitud y la exhibición de humanos" (p.289). Como concluye, "recuperar la memoria de este pasado no es simplemente una cuestión de justicia, es también necesario para poder visibilizar las raíces coloniales de imaginarios, prejuicios y actitudes que actualmente se viven hacia nuestros vecinos" (p.310). Asimismo, J.LL. Mateo escribe "Humanos por religión. Visiones marroquíes y europeas de la esclavitud en el encuentro colonial del siglo XIX" que se analiza la humanidad en la esclavitud a partir de las actitudes marroquíes frente a la esclavitud del siglo XIX, hasta la conferencia de Algeciras. Como concluía "la retórica colonial anti-esclavista no siempre se impuso tan claramente... sólo una circular francesa de 1922 hizo referencia a la prohibición de mantener mercados de esclavos..." (p.328). Y añadía "las visiones múltiples de los europeos mantenían una retórica contraria a la esclavitud.... Recurriendo a la explicación universalista de humanidad, pero al mismo tiempo, en ese mismo escenario los diversos agentes africanistas... estaban construyendo un nuevo sistema de clasificación... basado en jerarquías raciales y evolucionistas". V. Gaibar aborda "Estrategias de deshumanización de la población palestina: las campañas ciudadanas contra las parejas palestino-judías en Israel", y desarrolla la relevancia social de estas relaciones en Israel y como el sionismo europeo puede facilitar la deshumanización. Tras señalar que las relaciones de pareja entre población palestina y judía son cuestiones que despiertan interés, concluye que si esta cuestión ha tomado relevancia recientemente es porque "la pervivencia de estereotipos sociales refuerzan la incompatibilidad entre los diferentes grupos y limitan la posibilidad de mezclarse" (p.349). También revisa las campañas antimestizaje de Israel. Cierra sección y el libro M. Ojeda con su trabajo "Poderes no-Humanos en las relaciones entre humanos: los tzadikim judíos en Marruecos", texto en el que analiza la figura del tzadik en el judaísmo, estudia el misticismo judío en Marruecos y observa el impacto del colonialismo europeo en el culto a estas figuras. Entre sus conclusiones, el que "se han presentado unas creencias y prácticas culturales complejas que señalan la porosidad de la frontera entre lo humano y lo no-humano en el culto a los tzadikim en el judaísmo popular marroquí" (p.367). Para Ojeda, los judíos enviaban un mensaje claro a los colonizadores "sobre el poderoso y generoso aliado con el que contaba la comunidad" (p.368).

En definitiva, Humanidad. Categoría o condición. Un viaje antropológico es un libro de referencia para aproximarse a la diversidad cultural y humana, desde una óptica 
consciente de que las limitaciones que ha acarreado el concepto Humanidad las últimas décadas, deben subvertirse para ofrecer una lectura pluridimensional a un objeto de estudio complejo, superando limitaciones históricas y disciplinares. Con un elenco de investigadores excelente, el volumen ofrece un trabajo teórico y metodológico muy rico que abandera la pluridisciplinariedad, y la pluricausalidad. Y cabe decir que este reto renovado a la observancia y al análisis de las relaciones humanas con su entorno, nos concierne a todos, más cuando decodificar la manera en que las diferentes humanidades del mundo se relacionan con su entorno se ha convertido hoy en una tarea urgente. 